\title{
Agriculturas e naturezas no território rural: o caso da microbacia do Rio Sagrado em Morretes (PR)
}

Agricultures and natures in rural territory: the Rio Sagrado microbasin in Morretes (PR)

\author{
Carla Morsch Porto Gomes ${ }^{1}$ \\ Luciano Felix Florit ${ }^{2}$ \\ Cinthia Sena Abrahão ${ }^{3}$ \\ Carlos Alberto Cioce Sampaio ${ }^{4}$
}

\begin{abstract}
Resumo
$\mathrm{O}$ artigo tem como objetivo analisar os dados obtidos na pesquisa intitulada "Visões de natureza e práticas produtivas entre agricultores familiares da microbacia do Rio Sagrado" à luz da perspectiva do conceito de ecodesenvolvimento. Para tanto, explicita elementos teóricos e práticos que relacionam o diagnóstico desse lugar a um conjunto de mudanças de cunho mais amplo, concernentes ao Brasil. A análise se baseia nos aportes conceituais da geografia humana e da etnosociologia. Em termos de apontamentos finais, possibilita reforçar a ideia de que o desenvolvimento, como proposição includente, requer que se pense na diversidade de possibilidades que as diferentes marcas territoriais podem oferecer. Nesse sentido, aponta para a ruptura com a ideia de que exista apenas um caminho para as sociedades humanas serem classificadas como desenvolvidas.

Palavra-chaves: Ecodesenvolvimento; Território rural; Territorialidade; Rio Sagrado; Comunidades tradicionais.
\end{abstract}

\begin{abstract}
The article discusses results obtained in research about visions of nature and production practices among farmers of the Sacred River watershed. It does this in the light of the perspective of the concept of ecodevelopment. To this end, specifies theoretical and practical elements which link the diagnosis of this place with a set of changes that had happened in Brazil. The analysis is based on the conceptual contributions of human geography and ethnosociology. In terms of final notes, supports the idea that development as inclusive proposition requires to consider the diversity of possibilities that the various territorial imprints can offer. In this sense, points to the rupture with the idea that there is only one way for human societies are classified as developed.

Key words: Ecodevelopment, rural territory, territoriality, Rio Sagrado, traditional communities.

\footnotetext{
1 Doutoranda no Programa de Pós-Graduação (PPG) em Ciências Sociais em Desenvolvimento, Agricultura e Sociedade/ UFRRJ. E-mail: camorsch@ig.com.br

${ }^{2}$ Doutor em Ciências Sociais. Professor do PPG em Desenvolvimento Regional/FURB. E-mail: lucianoflorit@furb.br.

${ }^{3}$ Doutora em Geografia. Professora dos PPG em Desenvolvimento Territorial Sustentável e Turismo/UFPR. E-mail: cisena@terra.com.br

4 Pós-Doutor em Ecossocioeconomia. Professor dos PPG em Gestão Urbana/PUCPR, em Desenvolvimento Regional/FURB e Meio Ambiente e Desenvolvimento/UFPR. Pesquisador CNPq. E-mail: carlos.cioce@gmail.com.
} 


\section{Introdução}

Este artigo propõe analisar os dados obtidos na pesquisa intitulada "Visões de natureza e práticas produtivas entre agricultores familiares da microbacia do Rio Sagrado" à luz da perspectiva do conceito de ecodesenvolvimento (GOMES, 2010). A análise está focada em um espaço relativamente bem definido a partir de sua localização física, mas cujas características socioeconômicas e históricas apontam para uma realidade difusa. Nessa microbacia, tanto as escolhas produtivas quanto as visões de mundo dos atores inseridos nela apontam e reforçam o caráter de permanência de traços tradicionais, bem como novos vetores produtivos e conformações sociais.

Pequenos núcleos de produção rural situados no sudoeste da microbacia do Rio Sagrado, zona rural do município de Morretes, no Paraná, provocam o olhar do investigador para a leitura da convivência de camadas de modernidade e tradição, bem como sobre o diálogo intertemporal que representam. A fundamentação teórica para a construção da análise advém do campo da geografia humana e da etnoecologia, ciência que aborda os modos de vida tradicionais. Significa jogar olhares sobre uma configuração em que a paisagem relevante é aquela alterada historicamente pela ação humana, em movimentos que impõem relações de solidariedade e dependência. Há que se dizer aqui que não se trata de enfocar o espaço morto, fixo, não dialético, mas o espaço que expressa ação e relação, o espaço humano.

A relevância da reflexão sobre esse espaço está na coexistência dos processos recentes que marcam alguns dos espaços do rural no Brasil, como a invasão urbana caracterizada pelos chacareiros de fim de semana; a conversão dos pequenos agricultores brasileiros em produtores integrados ao mercado, cuja inserção torna-se focada na especialidade setorial frente à divisão do trabalho entre campo e cidade; e, por fim, produtores que não se integraram de forma definitiva ao mercado, e que reproduzem modos de vida "tradicionais", tanto em termos de práticas de cultivo como no que se refere à organização do cotidiano.

$\mathrm{Na}$ região delimitada como sudoeste da microbacia do Rio Sagrado fíca nítido tal configuração, através da própria composição demográfica, o que possibilita a discussão sobre dois conceitos, o de território rural e o de territorialidade. Território rural compreendido a partir das delimitações que extrapolam o caráter setorial, integrando modo de vida e de produção. Da mesma forma, territorialidade vista a partir das transformações no processo de ocupação recente, em confronto à ocupação original do lugar, tomada como apropriação material e simbólica do espaço, tornado território (RAFFESTIN, 1993). 
Pretende-se buscar nesta reflexão elementos capazes de alimentar a abordagem do desenvolvimento calcado na perspectiva do território. Em que medida o ecodesenvolvimento, como conceito e proposta, pode ser alimentado pela compreensão do processo de construção das territorialidades? Em que medida pode ser, por outro lado, instrumentalizador de uma perspectiva alternativa, de resistência à lógica expulsora que propulsiona populações enfraquecidas cultural e economicamente a uma tendência migratória rumo ao urbano?

Nesse sentido, o propósito deste artigo é trilhar esse caminho reflexivo tendo como elemento provocador a realidade heterogênea das comunidades do Rio Sagrado frente às intervenções baseadas nos princípios do ecodesenvolvimento. Tendo em vista realizar tal abordagem, o artigo foi estruturado em cinco partes, que tratam respectivamente da metodologia de trabalho na região, discutem e refletem sobre os aspectos históricos que afetam a transformação espacial, bem como os aspectos teóricos relacionados à temática, para por fim abordar os dados relativos ao diagnóstico territorial da microbacia do Rio Sagrado, em Morretes.

\section{Recorte do objeto e metodologia de abordagem da comunidade}

O sudoeste da microbacia hidrográfica do Rio Sagrado, zona rural do município de Morretes, no Paraná, abrange as comunidades de Candonga, Brejumirim, Canhembora e Rio Sagrado de Cima, compondo uma área de aproximadamente $84 \mathrm{~km}^{2}$, conforme ilustra a Figura 1. Atualmente, conforme Gomes (2010, p. 56), nessas comunidades residem 520 famílias, sendo que 270 são residentes e destas, 113 estão ligadas ao modo de vida tradicional ou camponês. Na sua maioria, correspondem às famílias mais antigas, com características semelhantes às formas de organização das sociedades camponesas tradicionais, que mantêm uma relação propriedade-famíliatrabalho com especificidades que as distinguem de outros agricultores familiares. Tais especificidades radicam principalmente na importância fundamental do grupo familiar no que diz respeito ao processo de transferência dos conhecimentos tradicionais, manutenção desse modo de vida, das formas de lidar com a terra e com as coisas da floresta, fazendo que os seus objetivos econômicos estejam intimamente relacionados às suas formas de sociabilidade.

Parcela significativa dessas comunidades tem participado de uma pesquisa-ação em curso, iniciada em 2006, denominada Zona de Educação para o Ecodesenvolvimento, na qual foi elaborado um diagnóstico sociobiofísico participativo com a intenção de se apontar demandas ecossocioeconômicas, bem como alternativas de soluções. Nesse processo ocorre o 
compartilhamento entre conhecimento científico e sabedoria local, o que envolve pesquisadores (GOMES, 2009).

Este artigo é também resultado de observações participantes e de etnografia, como método de levantamento de informações. Elas foram realizadas no âmbito do curso de Tecnologia em Agroecologia da Universidade Federal do Paraná durante o primeiro semestre de 2010, e através de pesquisa realizada por Gomes (2009). Nesta pesquisa foram realizadas dez entrevistas abertas com agricultores familiares, as quais foram gravadas e transcritas literalmente, tendo em vista facilitar a análise.

As entrevistas realizadas por Gomes (2009) buscaram descrever o processo de construção social da natureza por meio da investigação das escolhas produtivas dos agricultores. Entende-se por entrevistas abertas aquelas que possibilitam respostas livres, com espaços para explicações e comentários espontâneos por parte dos entrevistados.

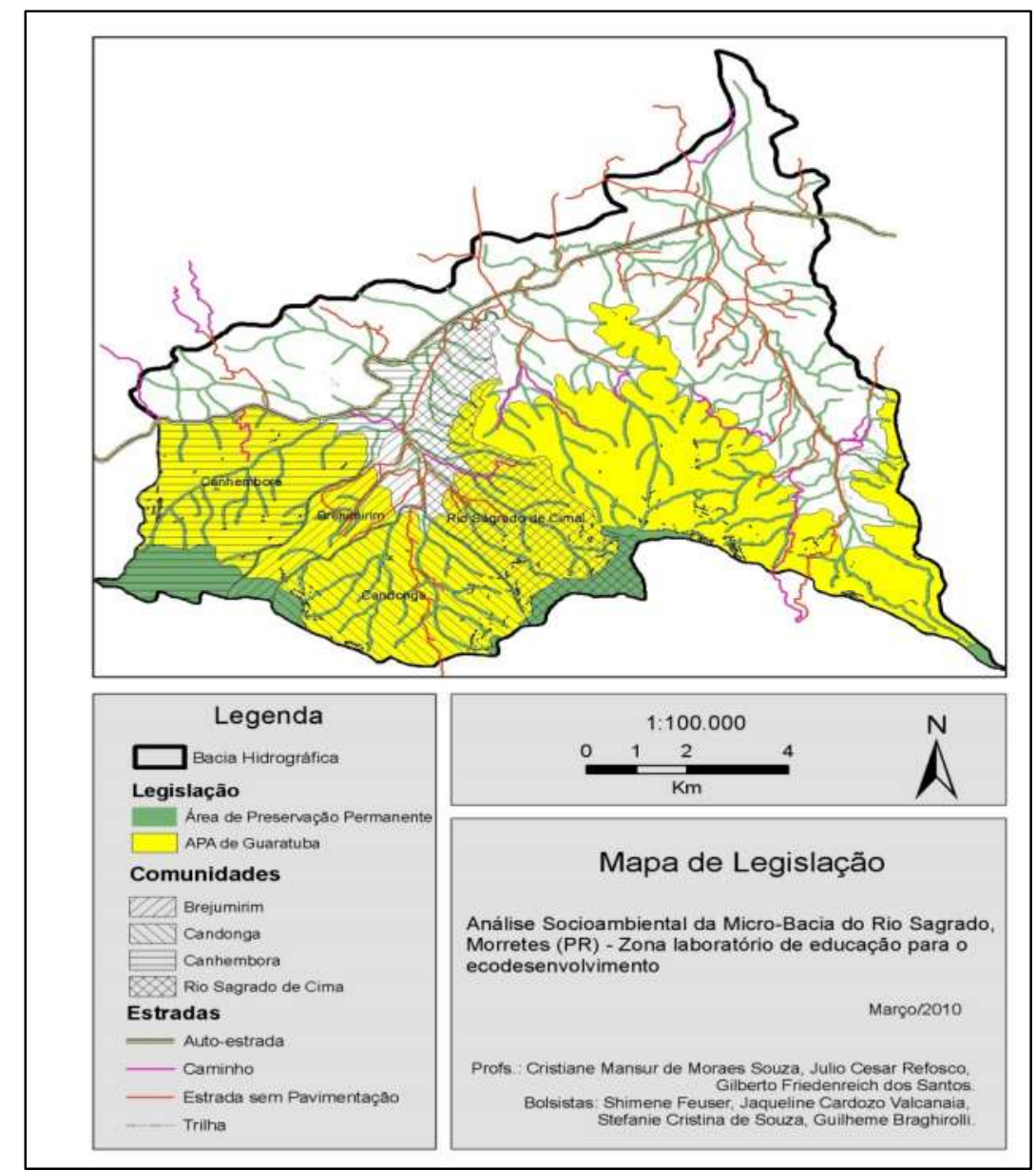

Figura I - Cartograma do sudoeste da microbacia do Rio Sagrado.

Fonte: Mansur, Santos, Refosco, Aumond, Feuser e Braghirolli, 2000. 
As entrevistas permitiram colocar em perspectiva a multiplicidade dos atores sociais e arranjos econômicos e produtivos que informam uma visão de mundo e, portanto, uma relação específica com o ambiente natural. Com isso, foi possível fazer uma aproximação com os valores que justificam as escolhas de algumas práticas em detrimento de outras. Essas conexões ensejam algumas reflexões sobre as distintas visões de natureza e os seus desdobramentos em práticas e orientações estratégicas para o desenvolvimento local. No entanto, é importante destacar que as narrativas em torno dessas relações expressam, de maneira geral, um conjunto de ideias em disputa que se relacionam aos diferentes posicionamentos sobre o papel da atividade agrícola nos processos de desenvolvimento.

\section{Morretes: do rural tradicional ao novo rural}

A planície litorânea, na qual está localizado o município de Morretes, representa a região pioneira da ocupação territorial do estado do Paraná. Ao longo dos séculos XVII e XVIII formou-se o povoado de Morretes, refletindo o encontro interétnico entre a população originária e os colonizadores de origem portuguesa. O caiçara do litoral brasileiro, fruto desse processo de colonização, preservou características de um modo de vida hoje considerado tradicional, haja vista que detém aspectos que diferem das formas modernas de organização socioeconômica.

Originalmente, a economia das comunidades caiçaras estruturou-se a partir da agricultura de subsistência, centrada na produção da mandioca e na pesca de curta distância. Conforme Adams (2000), os costumes e a forma de organização da economia não se assemelham àquelas verificadas nas sociedades indígenas, nem mesmo às moderno-industriais. Sendo assim, assumem especificidades inerentes a uma comunidade que institui relações próprias com o espaço a partir de suas formas de organização.

Tradicionalmente, a vida da população caiçara se baseava na agricultura de coivara, na pesca de pequena escala, no extrativismo vegetal e no artesanato. De acordo com Peroni (2004, p. 62), a agricultura de coivara implica na prática de realizar a limpeza através da queimada e posterior uso intensivo da terra, herança da cultura indígena no Brasil, que tem sido frequentemente classificada como itinerante. Essa classificação desconsidera que existam comportamentos diferentes entre os grupos, sendo que em parte dos casos a terra era abandonada, e em outros, deixada em pousio por um período.

A partir das práticas culturais, que envolvem a produção e valoração simbólica do espaço, pode-se dizer que houve a conformação do território caiçara. Vale dizer que é do processo de 
apropriação, transformação e significação do espaço, realizado por um grupamento humano, que advém a construção do território e a territorialidade. Para Raffestin (1998), o processo de apropriação se dá sob diversas formas e é determinante na definição histórica das transformações territoriais.

A população tradicional do litoral paranaense originou-se e foi submetida à influência das atividades mercantis em diversos períodos, desde a etapa da mineração no século XVII, que trouxe a primeira grande leva de imigrantes portugueses, ao ciclo da erva-mate, em fins do século XIX (FERREIRA, 1996). Prosperidade e estagnação deram o mote desse processo, sendo que a cada etapa de estagnação persistiu um processo de retomada das atividades tradicionais, em especial, aquelas de caráter rural. Assim, esse espaço foi sendo sedimentado a partir de uma configuração marcada pelo perfil das comunidades de lavradores e pescadores.

Em que pese a relevância dos núcleos urbanos do litoral paranaense até o último quartel do século XIX, inclusive de Morretes e Paranaguá, o processo de interiorização com a ocupação do primeiro planalto paranaense e o estabelecimento de Curitiba como capital da província ${ }^{5}$ marcaram um período de mudanças. Um fator essencial está relacionado à alteração das vias de ligação entre a capital e o litoral, o que se deu a partir da construção da estrada da Graciosa. Esta, por sua vez, terminou por promover o isolamento de Morretes $^{6}$ e sua decadência econômica. Isso porque a partir de 1873, a estrada da Graciosa passou a ligar diretamente Curitiba e Paranaguá, fazendo com que perdesse sentido o beneficiamento da erva-mate em Morretes, bem como induziu que a cidade saísse paulatinamente da rota dos viajantes (SCHIMINSKI, 2010).

Não por acaso, Santos (2006) releva o papel da técnica como elemento definidor da relação homem natureza, através da qual se dá o processo de realização da vida e, por conseguinte, da criação do espaço. É assim que o espaço assume a característica de território, através da animação definida pelo seu uso, isto é, pela ação humana. O território é constituído através de uma trama de relações complementares e conflitantes, tal como se presencia ao longo da história de formação do Paraná e, nesse caso, de Morretes.

Este processo de isolamento permitiu que se perpetuasse um modo de vida no qual não há separação entre o cultural e o econômico, permitindo, assim, caracterizar a população não urbana como tradicional. Importante frisar que consideramos tradicionais os grupamentos humanos diferenciados sob o ponto de vista cultural, que reproduzem historicamente seu modo de vida, de

\footnotetext{
${ }^{5}$ Em 1853, após longa contenda envolvendo Paranaguá e Curitiba, ficou estabelecido que a segunda exerceria o papel de capital da recém-criada província do Paraná.

${ }^{6}$ Conforme Leandro (2003), o primeiro grande boom econômico da região se deu a partir da década de 1830 , com o investimento dos lucros auferidos através do comércio negreiro, que envolveu as cidades litorâneas, na indústria ervateira.
} 
forma mais ou menos isolada, baseados na cooperação social e nas relações com a natureza (DIEGUES, 2001).

O adensamento populacional na região litorânea não coincidiu com o processo de ocupação e estabelecimento de alguns núcleos urbanos relevantes, todos eles com algum grau de vinculação com o exterior, em função da economia exportadora, tal como foi o caso de Paranaguá. Apenas a partir das décadas de 1960 e 1970 de fato ocorreu um aumento substantivo da densidade demográfica ao longo da costa litorânea no Brasil (MORAES, 1998, p. 147). Segundo Moraes (1998), duas ordens de fatores contribuíram para esse adensamento. Primeiramente, o reflexo de grandes aglomerações urbanas distantes até $200 \mathrm{~km}$ do litoral, permitindo que os moradores de renda elevada pudessem se tornar proprietários de segunda residência no litoral, o que foi possibilitado pela estruturação da rede de transportes que ligou o interior ao litoral. Um segundo fator foi responsável pelo adensamento de cidades portuárias e se relaciona ao incentivo às exportações brasileiras. Ambos os casos têm significado a destruição e o cerceamento, em maior ou menor grau, do modo de vida tradicional que foi predominante, em especial no ambiente rural.

Do ponto de vista das características naturais, é importante reforçar que o ecossistema costeiro possui características muito peculiares e frágeis, o que provocou um rápido efeito da ocupação sobre a sua conformação, resultando em problemas graves de ordem ambiental e social. Esse impacto é tanto mais expressivo quanto maior a expansão da ocupação para as áreas mais distantes do núcleo urbano original. Em contrapartida, esse processo tem se dado de forma acelerada e desordenada na planície litorânea paranaense e, ao mesmo tempo, tem significado um processo de estratificação e submissão da população nativa.

$\mathrm{O}$ crescimento urbano desordenado tem implicações em várias frentes, trazendo à tona as questões relativas a resíduos, abastecimento, inundações, saúde pública, dentre outras. Há de se entender que o espaço jamais aparece como um suporte neutro na vida das pessoas e dos grupos. É o resultado da ação humana que muda a realidade natural e cria paisagens, o que permite dizer que os lugares e as paisagens fazem parte da memória coletiva. A lembrança do que aconteceu no passado imprime valor sentimental a certos lugares (CLAVAL, 2002). Assim, pode-se dizer que as identidades individuais e coletivas estão fortemente ligadas à formação e ao desenvolvimento territorial. Em que pese não se buscar o congelamento da sociedade, o que se percebe é a relevância de se pensar modelos de desenvolvimento que levem em consideração os fatores objetivos e os subjetivos, que afetam a vida dos sujeitos em sociedade.

Nessa direção é que assume significado o fato de que a interpretação do território passou a exigir a leitura do hibridismo e das múltiplas dimensões relacionais que partem de diversos pontos que o compõem. Pensar na origem de um território, nos elementos que garantiram sua dimensão e 
forma, exige o resgate das características básicas que o compõem e o compuseram, deixando marcas espaciais. Estas poderiam ser sintetizadas no caráter político, o que, por sua vez, é expresso na relação entre os poderes instituídos, ditos macropoderes, e os micropoderes simbólicos, produzidos e vividos, que compõem o cotidiano da população. Ratificando assim, o que sintetiza Fraga (2006, p. 62) "o território é vivo [...] o espaço é sempre histórico, sua historicidade deriva da conjunção entre as características da materialidade territorial e as características das ações".

A construção dos territórios que se configuram na região sudoeste da microbacia do Rio Sagrado guarda as contradições do processo histórico que promoveu a modernização e urbanização intensa no estado Paraná, processo que tem expulsado a população rural tradicional de seus territórios originais. É importante que se frise o termo expulsar, à medida que o que se observa não se trata de um processo de mudança no modo de vida, como parte da dinâmica inerente à cultura, mas a inviabilização da permanência, inclusive para aquela parcela que deseja preservar as tradições.

De outro lado, também expressa incompletude do processo considerando a convivência, não sem tensão, de diversos modos de vida. Desde os ocupantes urbanos que utilizam o espaço rural para ampliar seu contato com a natureza, para o descanso e lazer, até os produtores rurais integrados ao mercado de forma definitiva, bem como aqueles que preservam os traços da tradição camponesa.

Conforme Santos (1982, p.1),

[...]somente a história da sociedade mundial aliada à sociedade local pode servir como fundamento da compreensão da realidade espacial e permitir a sua transformação a serviço do homem. Pois a história não se escreve fora do espaço e não há sociedade a-espacial. $\mathrm{O}$ espaço, ele mesmo, é social.

Nesse sentido é que se pode remeter à chamada era da globalização, na qual os fluxos de capitais, mercadorias e pessoas tornaram-se potencializados de forma antes impensável. Nesta também se instalou uma nova lógica de valorização do local, sendo que o culto do globalismo, bem como do localismo, reproduzemum efeito diluidor das instâncias básicas de atuação política e da própria atividade política (MORAES, 2005). Isso significa dizer que a reflexão sobre território e territorialidade nas comunidades precarizadas ou desprivilegiadas nos processos de transformação econômica e cultural contemporâneos comporta a proposição de subsídio à transformação política da realidade.

Para Haesbaert (2007), a fragmentação representa o avesso da moeda dos processos de globalização. Fragmentação que é excludente para uma parcela significativa da população brasileira, e mais especialmente para esta porção "tradicional" que resiste em vários lugares, como 
no território do Rio Sagrado. O sentido globalizador do capitalismo, que lhe é inerente, como apontam Marx e Engels no Manifesto Comunista, tem um caráter extensivo na incorporação progressiva de novos territórios, e intensivo na transformação e reordenação dos modos de vida em espaços consolidados (HAESBAERT, 2007, p. 41).

A revolução científico-tecnológica a partir dos anos 1970 associada à “crise ambiental”, bem como a velocidade das novas mudanças e a presença/difusão de redes de conexão complexas (redes eletrônicas de comunicação), criaram uma nova articulação local-global. Essa nova articulação é ainda mais profunda que as transformações tempo/espaço promovidas pela introdução da tecnologia do pós-segunda guerra mundial, baseada na conversão da tecnologia da guerra fria para o campo da produção e consumo de bens e serviços. Esses novos processos viabilizaram a mercantilização das imagens dos lugares de forma ainda não experimentada na história humana.

Conforme Becker (2001), merece destaque a nova abordagem em relação à natureza a partir deste momento. Esta atinge o significado de valor futuro, de reserva de valor, o que também se reflete na oferta turística, a partir do surgimento de um segmento turístico especial, o ecoturismo, e posteriormente do chamado turismo de base comunitária ${ }^{7}$. Essa nova forma de valorização do "natural" e do "cultural" teve incidência significativa sobre os países periféricos, tropicais e mediterrâneos, trazendo simultaneamente potencial de desenvolvimento, mas muitas vezes assumindo uma faceta perversa ao alimentar conflitos relacionados ao uso do território, especialmente em função da exclusão de grupos populacionais historicamente vinculados a tais localidades, seja pela imposição de novos valores, seja pela não participação do processo.

Nesse contexto, a zona costeira brasileira reassumiu um papel estratégico, que havia perdido ao longo do processo de industrialização, que priorizou o eixo interior, liderado pela cidade de São Paulo e pela nova capital, Brasília. Tal caráter estratégico está relacionado aos grandes circuitos logísticos de circulação de âmbito global e planetário. A partir deles, o novo horizonte tecnológico de intervenção passou a posicionar a zona costeira como área para onde conflui uma gama de recursos, bióticos e abióticos, em pleno processo de valorização. Com ênfase nos aspectos físicos, essas dimensões fizeram reascender o ambiente costeiro ao campo da geopolítica (BECKER, 2001).

A esse processo de revalorização se vincula a associação entre proximidade do campo e qualidade de vida, que se torna crescentemente um requisito das classes média e alta de grandes cidades. O que, por sua vez, tem alimentado uma nova ruralidade no Brasil. Para Silva e Del Grossi (2000, p.166), o novo rural pode ser caracterizado como "uma nova onda de valorização do espaço rural, capitaneada por questões ecológicas, preservação da cultura 'country', lazer, turismo ou para

\footnotetext{
${ }^{7} \mathrm{O}$ turismo comunitário surge como uma alternativa às modalidades do turismo existentes, inclusive o ecoturismo, quando estas não relevam ou, ainda, menosprezam os modos de vida tradicionais, como se não fosse possível estes serem protagonistas da atividade turística (SAMPAIO, 2010).
} 
moradia". Nesse contexto, a preservação ambiental se transforma em um campo de oportunidades para novos investimentos, que em geral excluem as parcelas mais frágeis da população, em especial os ocupantes tradicionais.

\section{Ecodesenvolvimento ou Desenvolvimento Territorial Sustentável}

O ecodesenvolvimento ou desenvolvimento territorial sustentável pode ser compreendido como uma estratégia de desenvolvimento que privilegia o território como espaço concreto pensado numa escala intergeracional, onde pessoas viveram, vivem e viverão sobre princípios da sustentabilidade, isto é, as gerações futuras têm os mesmos direitos à vida que as atuais. Atualmente, não é tarefa simples manter a identidade de territórios isolados, rurais e costeiros, afastados da sede de seus municípios, no entanto esses podem estabelecer acordos ou arranjos para melhor conservar seus modos de vidas. Nesses territórios o desenvolvimento não se submeteria necessariamente à supremacia econômica, mas ao que se denomina por desenvolvimento à escala humana, isto é: um desenvolvimento baseado no que o território estabelece como padrão de sua cultura (CARRIÈRE e CAZELLA, 2006; PECQUER, 2006; SAMPAIO et al., 2010).

Para a etnosociologia, o território é o espaço concreto da natureza no qual determinada comunidade reivindica e garante aos seus membros a possibilidade de direitos estáveis de acesso à totalidade, ou parte da biodiversidade existente, para os que nela desejam estar ou são capazes de utilizar. Assim, o território fornece os meios de subsistência e de produção e, ao mesmo tempo, cria a dinâmica social que o diferencia - modos de vida próprios -, tanto quanto os aspectos físicos que o limitam. O território é o locus de sistemas de representações, identidades, símbolos e mitos que populações tradicionais constroem com o que agem sobre o ambiente (DIEGUES, 2000).

A etnosociologia e a geografia dialogam e complementam as perspectivas para interpretar a multidimensionalidade do conceito de território. Como desdobramento, a perspectiva do desenvolvimento territorial sustentável releva modos de vida urbanos e não urbanos (como alternativas aos padrões da sociedade de consumo) e que podem sinalizar aprendizados sobre a sustentabilidade do desenvolvimento humano, mesmo se essas comunidades são tidas, sob a lógica econômica, como modos de vida, de produção e de conhecimento obsoletos.

O desenvolvimento territorial sustentável privilegia experimentações, assim como as complexidades do cotidiano, que superam as contradições inerentes à mudança paradigmática que se deseja - ou na velocidade que se deseja - quando se pensa nas limitações do utilitarismo 
econômico, que privatiza os lucros de curto prazo e socializa os prejuízos socioambientais de médio e de longo prazo (SAMPAIO, 2010).

Da mesma forma, o território delineia seus contornos sociais e biofísicos a partir do espaço, dando concretude aos elementos até então abstratos, como aponta Raffestin (1993). Assim, o desenvolvimento territorial sustentável se constrói baseado nos padrões de interações entre sistemas culturais e ecológicos, denominados modos ou estilos de vida. Para Haesbaert (2009), o território representa humanamente a possibilidade da experiência integradora, sistêmica, mas nunca total, mesmo porque o território não é imune à escala global. Tal experiência torna impositiva a articulação dos atores sociais, em várias escalas, que podem partir do local até o global.

O território revela o caráter híbrido da experiência humana em sociedade, já que não existem modos de vidas puros, mesmo porque o conceito de cultura é dinâmico. Os modos de vida podem ser definidos por critérios geográficos - território isolado -, culturais - compartilhando costumes, usos e tradições, hábitos -, ou por funções socioeconômicas - variando por modos de produção (GEERTZ, 1989). Os modos de vida são resultados da maneira pela qual o homem se apropria da natureza, ou, segundo Haesbaert e Limonad (2007), na relação que reúne aspectos que integram sociedade e natureza; política, economia e cultura; materialidade e idealidade. Mesmo que se perceba a preponderância do aspecto econômico, central e reforçado na economia de mercado, nenhum conceito que parta puramente das relações econômicas, ou de outra dimensão territorial, poderá instrumentalizar a ação sobre a realidade diversa que se expressa no território do Rio Sagrado, em Morretes. É isso que justifica a fusão de três conceitos em um novo conceito, desenvolvimento, território e sustentável.

As contradições inerentes ao sistema capitalista se recolocam permanentemente em novas escalas. Há, por assim dizer, uma espacialização das formas capitalistas preenchidas por conteúdos essenciais unificadores, mas também por conteúdos específicos que reconstituem as diferenças em novo patamar. Segundo Santos (2006, p.80), “o desenvolvimento desigual e combinado é, pois, uma ordem cuja inteligência é apenas possível mediante o processo de totalização, isto é, o processo de transformação de uma totalidade em outra totalidade". Assim, a divisão do trabalho, movida pela produção e por seus impulsos dinâmicos, produz a cada momento um novo movimento e uma nova função aos lugares.

Oficialmente, povos e comunidades tradicionais são considerados como:

[...] grupos culturalmente diferenciados e que se reconhecem como tais, que possuem formas próprias de organização social, que ocupam e usam territórios e recursos naturais como condição para sua reprodução cultural, social, religiosa, ancestral e econômica, utilizando conhecimentos, inovações e práticas gerados e transmitidos pela geração (BRASIL, 2001). 
Seus modos de vida podem ser definidos por critérios geográficos - território isolado -, culturais - compartilhando costumes, usos e tradições, hábitos -, ou por funções socioeconômicas (GEERTZ, 1989). Comunidades e modos de vida se confundem e se identificam como extrativistas, ribeirinhas, pescadores artesanais, pequenos agricultores familiares, povos originários e quilombolas.

Tais comunidades, mesmo que possuam descaracterizações, são ainda identificadas como tradicionais por conservarem padrões de modos de vida, tais como, simbolismos, costumes e funções socioeconômicas (SAMPAIO, 2010). Mesmo porque, a autenticidade não é um conceito fechado em si; ele é negociável em seu significado, isto é, todas as culturas que se tornaram viáveis ao longo do tempo foram refazendo a si próprias. Da mesma maneira, as culturas tradicionais não são estáticas, estão em constante mudança, seja por fatores endógenos ou exógenos (GREENWOOD, 1982; COHEN, 1988; NASH, 1996; DIEGUES, 2000). Imaginar que exista atualmente a predominância de uma cultura ocidental homogênea seria um equívoco sobre tais argumentos.

Sob a visão biocêntrica, que enseja o mito da natureza intocada, não há desenvolvimento sem impacto ambiental, o que substancia a lei da entropia (LEFF, 2009), e sugere a seguinte questão: o quanto de desenvolvimento pode ser considerado territorialmente sustentável?

Há que se encontrar uma lógica que se distancie da lógica antropocêntrica, quando esta se baseie na racionalidade urbana-industrial-consumista,que conduza um padrão de desenvolvimento baseado na desigualdade socioeconômica e na degradação ambiental. Com efeito, entre países com muito elevado, elevado, médio e baixo índice de desenvolvimento humano - IDH (PNUD, 2010), constata-se a contradição entre o elevado IDH associado, frequentemente, a também elevada pegada ecológica ${ }^{8}$. Pode-se dizer que os modos de vida de populações tradicionais se aproximam mais do que se pode esperar do conceito de sustentabilidade. Isso não significa afirmar que as atividades das sociedades não industriais sejam totalmente adaptativas, no sentido de tender ao equilíbrio entre sistemas sociais e ecológicos, enquanto que a sociedade industrial moderna seria não adaptativa (FOLADORI e TAKS, 2004). Contudo, sim, é possível dizer que, de modo geral, o imaginário popular das populações tradicionais encontra mecanismos próprios de conservação da biodiversidade, podendo determinar lugares da floresta e determinadas espécies de fauna e flora como sagrados, restringindo, assim, áreas de visitação ao turismo (DIEGUES, 2000).

\footnotetext{
${ }^{8}$ Pegada ecológica é o conjunto de indicadores agregados que aponta a incapacidade de carga do planeta para suportar o atual estilo de desenvolvimento (WACKERNAGEL e REES, 2001).
} 


\section{Modos de Vida e de Produção Rural Tradicional no Sudoeste da Microbacia do Rio Sagrado}

Os modos de vida e os distintos modelos produtivos que convivem nas comunidades do Rio Sagrado possibilitam refletir sobre a coexistência de diferentes racionalidades e as tensões inerentes a esse processo dentro de um território rural. Considerando suas características sociais e fundiárias (predominância de pequenas e médias propriedades), a maioria dos agricultores se constituem como agricultores familiares. Categoria que compreende o grupo familiar como responsável pelo trabalho no estabelecimento e ao mesmo tempo é como proprietário dos meios de produção (WANDERLEY, 1996). No entanto, há também uma pequena parcela, não desprezível em termos de escala de produção e propriedade da terra, que se organiza em atividade produtiva a partir da lógica empresarial, com a contratação de funcionários e produção totalmente voltada ao mercado.

Nesse sentido, foram identificados os modelos de produção que nos informam visões de mundo diferenciadas e, consequentemente, formas variadas de apropriação da natureza. Em outras palavras, as configurações que se estabelecem a partir do vínculo intrínseco entre as construções sobre natureza e as concepções normativas que orientam os modelos produtivos (Quadro 01). Essa caracterização aproxima-se do tipo ideal weberiano na mediada em que é uma organização ideal das relações sociais a fim de torná-las inteligíveis, através do desenho de sua racionalidade interna (WEBER, 1999). Esse recurso não interessa como um fim em si mesmo, mas como um meio de aprofundar a compreensão do problema de análise, aproximando-se ou afastando-se do seu conteúdo empírico (ARON, 1993).

\begin{tabular}{|l|l|l|l|}
\hline $\begin{array}{l}\text { Tipo de } \\
\text { agricultura }\end{array}$ & $\begin{array}{l}\text { Fundamento } \\
\text { teórico }\end{array}$ & Visão de natureza & Concepção normativa \\
\hline $\begin{array}{l}\text { Agricultura } \\
\text { moderna }\end{array}$ & Mecanicismo & $\begin{array}{l}\text { Visão utilitarista e } \\
\text { atomista.Considera apenas os } \\
\text { elementos químicos e físicos }\end{array}$ & $\begin{array}{l}\text { Controlar a natureza; } \\
\text { maximizar os ganhos econômicos; } \\
\text { natureza como recurso. }\end{array}$ \\
\hline $\begin{array}{l}\text { Agricultura } \\
\text { camponesa }\end{array}$ & $\begin{array}{l}\text { Conhecimento } \\
\text { tradicional }\end{array}$ & $\begin{array}{l}\text { Percepção hereditária da } \\
\text { natureza }\end{array}$ & $\begin{array}{l}\text { A natureza como provedora do } \\
\text { sustento da família; } \\
\text { o rural e a terra como espaço social } \\
\text { determinante das estratégias de } \\
\text { reprodução social. }\end{array}$ \\
\hline $\begin{array}{l}\text { Agricultura } \\
\text { orgânica }\end{array}$ & $\begin{array}{l}\text { Experiência da } \\
\text { agricultura } \\
\text { tradicional: } \\
\text { história natural } \\
\text { (evolucionismo) }\end{array}$ & $\begin{array}{l}\text { Natureza biológica composta } \\
\text { por organismos vivos }\end{array}$ & $\begin{array}{l}\text { Produzir alimentos saudáveis; } \\
\text { relação mais simbiótica entre os } \\
\text { sistemas agrícolas e os } \\
\text { ecossistemas locais. }\end{array}$ \\
\hline
\end{tabular}

Quadro 1 - Visões de natureza e concepções normativas presentes no local de estudo.

Fonte: Adaptado de Florit (2004). 
Uma parte expressiva dos agricultores do Rio Sagrado, principalmente a parcela de moradores mais antigos das comunidades, organizam-se a partir de formas tradicionais de sociabilidade e produção, semelhantes às elencadas em importantes trabalhos sobre o campesinato como: i) autonomia relativa em relação à sociedade como um todo; ii) importância estrutural do grupo doméstico; iii) um sistema econômico de autarquia relativa; iv) uma sociedade de interrelacionamentos; v) produção para o autoconsumo; vi) atividade produtiva como modo de vida e não como negócio;vii) encontra-se ligado à terra por laços de tradição e sentimento;viii) o trabalho é realizado pelo família (ABRAMOVAY, 1992; WANDERLEY, 1999; LAMARCHE,1993).

As formas de organização camponesa das comunidades englobam essas características. Há de se ressaltar, portanto, a forma de inserção parcial na sociedade e sua racionalidade econômica particular, ou seja, sua capacidade de estruturar a vida em torno de um conjunto de normas próprias e específicas, em que o trabalho e a vida funcionam como um organismo único. Sua integração aos mercados é parcial; a agricultura de subsistência (policultivos) permite a possibilidade de retirar-se do mercado sem comprometer sua reprodução social. A comercialização e formação dos preços são definidas pelas condições locais e laços afetivos, já que grande parte da clientela é formada por vizinhos ou comerciantes locais, em muitos casos consolidada por relações de reciprocidade e/ou uma economia das trocas. Dentro desse grupo de agricultores tradicionais, deve-se destacar o cultivo da mandioca e banana como principal fonte de sustento das propriedades que, por sua vez, revela a manutenção do traço característico da cultura caiçara.

É que a gente não tá bom para trabalhar como antes, mas a gente compra muito pouca coisa por que tudo a gente produz aqui, né? (entrevistado 1).

Hoje não é só pra nós mesmo, quase não vende nada. Outros tempos já vendi feijão, milho e café, mas só por aqui mesmo. Hoje o pessoal tem pouca coisa, antigamente todo mundo tinha e plantava bastante coisa. Hoje a gente vende para um ou outro do pessoal aqui ou troca volta e meia para se ajudar (entrevistado 2).

A ligação desse grupo com o território vincula-se à sua história de vida e à tradição do trabalho na terra. Revela, portanto, uma concepção de natureza geracional, na qual está implícita em todas as falas a força do "cuidado" com o lugar e um sentimento de gratidão em relação ao que natureza permite extrair e cultivar. Nesse sentido, observa-se uma subjetividade que explicita uma correlação intrínseca entre trabalho/família/ natureza (terra e floresta) que se expressa em práticas que esboçam um desejo de preservar que possibilite as próximas gerações permanecer. 
A gente planta e coisa, mas sem agredir tanto a natureza, por que hoje em dia a turma quer que desmate tudo e fique só a terra, tudo limpo. Nós não, a gente planta e conserva as árvores e as nascentes. [...] Aqui o mato dá tudo para gente, não dá para fazer roça muito grande e nem pode, não quero aumentar. Além disso, não largo o meu pedaço de chão. Quero deixar isso para os meus sobrinhos e eles é que têm que ver mais tarde o que vão fazer, mas tem que cuidar para não perder (entrevistado 2).

Um elemento que tem dificultado a reprodução social desse grupo se refere ao aumento da circulação de dinheiro na comunidade, relacionado à entrada de novos agentes econômicos na comunidade, a exemplo dos chacareiros, moradores de fim de semana. Estes passaram a demandar dos moradores locais a prestação de serviços domésticos de limpeza, jardinagem, dentre outros, que são pagos em dinheiro, reproduzindo a prática dominante nas sociedades de mercado. Tal processo torna a dependência do dinheiro algo mais presente na vida da comunidade, ao mesmo tempo em que traz para o contexto os valores simbólicos que estão vinculados à economia monetária.

De outro lado, identificou-se também o agricultor moderno melhor incorporado ao mercado e inspirado no modelo agrícola da produção que privilegia o monocultivo e o uso de defensivos químicos. A visão predominante nesse grupo expõe a intenção de que o produtor passe a depender cada vez menos das variações do meio ambiente natural e possa exercer maior controle sobre a natureza, por meio da tecnologia. Em sua grande maioria, esse modelo produtivo dedica-se ao monocultivo de médio porte de frutas e legumes, principalmente chuchu e banana. Os proprietários residem em Curitiba e empregam mão de obra local, destinando a sua produção para o Ceasa de Curitiba.

Por ser uma comunidade em considerável fragilidade socioeconômica, existem poucos agricultores familiares que conseguiram recursos para se modernizar. Contudo, grande parte desse grupo que incluímos dentro da racionalidade da agricultura moderna faz uso de fertilizantes e defensivos agrícolas e privilegia o cultivo de determinada espécie, como a palmeira-real, em função das suas vantagens econômicas. Esse agricultor adota, mesmo que maneira incompleta, um sistema cada vez mais adaptado ao modelo de modernização agrícola, encontrando-se crescentemente subordinado às necessidades e dependências das cadeias de valor dos sistemas agrícolas convencionais.

\footnotetext{
Ah sim, queria investir mais e aumentaria a produção, tem uns defensivo bom e que deixa a planta bem bonita, tem que comprar para garantir o produto bonito para o mercado (entrevistado 4).

Maior dificuldade é falta de apoio.Poderia produzir muito mais e não temos muita tecnologia e falta acesso ao crédito; tem que comprar o que precisa para continuar produzindo(entrevistado 5).
} 
Há um profícuo debate em torno da modernização agrícola, que não convém aprofundar no âmbito deste artigo, no entanto, uma leitura mais técnica conduziria a uma análise das mudanças apenas de caráter tecnológico, como máquinas e insumos, que tem por objetivo ganho de rendimento no processo produtivo. Por certo, esse processo trata-se de mudanças mais estruturais e complexas que não se restringe ao uso máquinas, mas ao processo de transformação capitalista da agricultura. O produtor busca depender cada vez menos das variações e da benevolência da natureza, busca cada vez mais adaptá-la as suas necessidades. Consequentemente, a tendência da nova agricultura é de forte utilização de defensivos agrícolas, tendência de expansão da área cultivada, monocultivo e preocupação intensa com o aumento da produtividade (TEIXEIRA, 2005).

Diante dos desafios socioambientais, a busca por alternativas produtivas que possam ser denominadas como mais sustentáveis é crescente, porém ainda não expressiva nas comunidades do Rio Sagrado. Essa parcela dos agricultores que está empenhada em produzir em consonância com tais preceitos se autoproclama como agricultores orgânicos. Tal corrente de agricultura se justifica, de forma geral, pela crescente necessidade de criar um sistema alimentar mais confiável em decorrência da crítica a um modelo que produz inseguranças em relação à qualidade dos alimentos e às consequências ambientais do modelo convencional de produção (FLORIT, 2004). Como a maioria desses agricultores possui fortes relações de parentesco com as formas de organização tradicionais, há uma sobreposição dessa racionalidade com forte presença de um posicionamento político-crítico aos modelos convencionais e que ressignificam a valorização dos saberes tradicionais para um discurso embasado nas narrativas contemporâneas sobre desenvolvimento sustentável.

A diferença é o manejo. Não tem que se preocupar com os químicos, não pode usar nada. E na sua alimentação também, o pessoal da agricultura convencional come qualquer coisa e a minha produção vai para mesa da minha família. É outra maneira de viver (Entrevistada 7).

A gente se preparou para produzir dessa maneira. Fiz um curso na Emater, a gente aprende sobre sustentabilidade ambiental e sobre alimentação saudável, assim a gente se prepara para se justificar por que fazemos desse jeito, que não é muito diferente do jeito que os pais da gente faziam (entrevistado 9).

Em suma, a agricultura moderna, resultado do avanço do capitalismo no campo, revela uma concepção de mundo que compreende as estratégias econômicas como uma esfera cada vez mais diferenciada da sociedade e desobrigada de questões sociais, na qual os agentes devem informar um comportamento baseado em escolhas racionais e lucros individuais. Todavia, reduz a ideia de natureza a signos de valor monetário como recurso e capital. As outras tipologias (tradicional e 
orgânica) desconstroem a imagem do homem racionalmente motivado por objetivos puramente econômicos na medida em que expressam outras formas de sociabilidade, as quais a natureza não pode ser analisada sobre o ponto de vista quantificador da economia, mas sobre aspectos relacionados a laços emocionais com a terra (natureza) e relações de reciprocidade e tradição, além de preocupações com a qualidade dos alimentos e os reflexos das práticas produtivas no ambiente, considerando uma perspectiva geracional.

\section{Considerações Finais}

O sudoeste da microbacia do Rio Sagrado expressa características de grande valor socioeconômico, ambiental e sociocultural, muito embora esse valor não remeta às tendências de desenvolvimento tidas como bem-sucedidas de acordo com os parâmetros predominantes da sociedade capitalista.

As características que lhe dão esse valor resultam de uma peculiar (embora não exclusiva do caso analisado) construção da territorialidade que, se reconhecidos e potencializados, podem alicerçar um modelo de desenvolvimento não expulsor dos setores desfavorecidos das áreas, cujas amenidades "naturais" tendem a ser mais cobiçadas. Pelo contrário, a permanência dessas populações pode representar não apenas um exemplo de resistência, mas uma concepção alternativa do desenvolvimento, marcada pelo hibridismo e a convivência entre modos de vida diferentes, incluindo uma diversidade no modo de percepção e utilização dos recursos naturais disponíveis.

Dentro dessa diversidade, modos de vida com uma concepção de uso sustentável da natureza representam modelos que devem ser valorizados e apoiados. Esses modos de vida atuam no sentido inverso da lógica de mercado, que fragiliza crescentemente as populações tradicionais e continua promovendo o processo migratório do rural para o urbano de parcelas importantes da sociedade brasileira que poderiam persistir no campo, especialmente os jovens.

Os próprios agricultores familiares locais expressam essa diversidade. Não é novidade que o mundo rural contempla uma multiplicidade de atores, cuja classificação é difícil, se consideradas apenas variáveis simplificadoras, tais como propriedade ou não dos meios de produção; integração ou não ao mercado. O rural continua sendo um território da diversidade, e o caso do sudoeste da microbacia do Rio Sagrado expressa isso de modo intenso. Condensa, de forma cada vez mais evidente, elementos do passado e do contemporâneo, demandas infraestruturais elementares como regularização fundiária, ao mesmo tempo em que incorpora novas formas de expressão cultural midiatizadas. 
O ecodesenvolvimento aparece então como uma perspectiva que, aliada às análises que permitem compreender construção da territorialidade dos atores envolvidos, pode canalizar potencialidades enfraquecidas e torná-las um exemplo a ser reconhecido e apreciado pela sua contribuição a um padrão de desenvolvimento equilibrado em termos ambientais, econômicos, culturais e populacionais, especialmente no que se refere a frisar que a ideia de um único caminho para o desenvolvimento constitui um elemento ideológico do sistema, que não condiz com a diversidade e riqueza de possibilidades que encontramos no território brasileiro.

Isso implica dizer que o hibridismo encontrado nos modos de vida rurais são expressões da busca por um desenvolvimento na escala do território, estabelecendo um padrão para uma cultura sustentável diferente dos estilos de vida tipicamente urbanos que parecem ignorar os limites da capacidade de carga do planeta para absorver todos os impactos ambientais.

\section{Referências}

ADAMS, C. As populações caiçaras e o mito do bom selvagem: a necessidade de uma nova abordagem interdisciplinar. Revista de Antropologia (São Paulo), São Paulo, v. 43, n.1, p. 145182,2000 .

ARON, R. As etapas do pensamento sociológico. São Paulo: Martins Fontes, 1993.

BECKER, B. Políticas e planejamento do turismo no Brasil. Caderno Virtual de Turismo, v. 1, n. $1,2001$.

BRASIL. Lei $n^{0}$ 6.040, de 7 de fevereiro de 2007. Brasília, DF: Presidência da República, 2008. Disponível em: <http://www.planalto.gov.br/ccivil_03/_Ato2007-2010/2007/Decreto/D6040.htm>. Acesso em: 24 mai. 2010.

CARRIÈRE, J.; CAZELlA, A. A. Abordagem introdutória ao conceito de desenvolvimento território. In: Desenvolvimento Territorial Sustentável: conceitos, experiências e desafios. Eisforia, Florianópolis, v.4, n. especial, p. 1-336, dez. 2006.

CLAVAL, P. "A Volta do Cultural" na Geografia. In: Mercator - Revista de Geografia da UFC, ano 01, n. 1, 2002. Disponível em: <http://mercator.ufc.br/revista $>$. Acesso em: 07 set. 2005.

COHEN, E. Authenticity and commoditization in tourism. Annals of Tourism Research, v. 15, n.3, p. 371-386, 1988.

DIEGUES, A. C. S. O mito moderno da natureza intocada. São Paulo: Hucitec, Núcleo de Apoio à Pesquisa sobre Populações Humanas e Áreas Úmidas Brasileira. USP: 2000.

DIEGUES, A. C.; ARRUDA, R. S. V. Saberes tradicionais e biodiversidade no Brasil. Brasília: MMA, 2001. (Série Biodiversidade). 
FERREIRA, J. C. V. O Paraná e seus municípios. Maringá: Memória Brasileira, 1996.

FLORIT, L. F. A reinvenção social do natural: natureza e agricultura no mundo contemporâneo. Blumenau: Edifurb, 2004. 192 p.

FOLADORI, G. e TAKS, J. Um olhar antropológico sobre a questão ambiental. MANA: Estudos de Antropologia Social (UFRJ), v. 10, n. 2, p. 323-348, 2004.

FRAGA, N. C. Mudanças e permanências na rede viária do Contestado: uma abordagem acerca da formação territorial no sul do Brasil. Tese (Doutorado em Meio Ambiente e Desenvolvimento). Curitiba: UFPR, 2006.

GEERTZ, C. A interpretação das culturas. Rio de Janeiro: LTC, 1989.

GOMES, C. M. P.Visões da natureza e práticas produtivas entre agricultores familiares da microbacia do Rio Sagrado - Implicações para o ecodesenvolvimento. Trabalho de Conclusão de Curso (Bacharelado em Ciências Sociais). Blumenau: FURB, 2010.

GREENWOOD, D. Cultural authenticity. Cultural Survival Quarterly, v. 6, n. 3, p. 27-28, 1982.

HAESBAERT, R. O mito da desterritorialização- Do fim dos territórios à multiterritorialidade. Rio de Janeiro: Bertrand Brasil, 2007.

. Dilema de conceitos: espaço-território e contenção territorial. In: SAQUET, Marcos Aurélio; SPOSITO, Eliseu Silvério. Territórios e territorialidades - Teorias, processos e conflitos. São Paulo: Expressão Popular, 2009.

HAESBAERT, R.; LIMONAD, E. O território em tempos de globalização. In: Etc., Espaço, tempo e crítica.Revista Eletrônica de Ciências Sociais Aplicadas e outras coisas. Disponível em: $<$ http.://www.uff.br/etc.>. Acesso em: ago. 2007.

LEFF, E. Saber ambiental: sustentabilidade, racionalidade, complexidade e poder. Petrópolis: Vozes, 2009.

MANSUR, C. de M. S.; SANTOS, G. F.; REFOSCO, J. C.; AUMOND, J.J.;FEUSER, S.; BRAGHIROLli, G. Pósfácio. In: SAMPAIO, Carlos A. C.; MANSUR, Cristiane de M. S.; HENRÍQUEZ, Christian Zuñiga. Turismo comunitário solidário e sustentável: da crítica as ideias e das ideias à pratica. Blumenau, Brasília: EDIFURB, Ministério do Turismo, 2010. Prelo.

MORAES, M. E. S. de. A ocupação antrópica e as questões ambientais no ecossistema restinga- O caso do perímetro urbano do município de Paranaguá. In: LIMA, R. Eugênio; NEGRELE, R. R. B. (Orgs.). Meio ambiente e desenvolvimento no litoral do Paraná. Brasília: UFPR, 1998.

NASH, D. Antropology of tourism. New York: Pergamon, 1996.

PERONI, N. Agricultura de pescadores. In: BEGOSSI, Alpina (Org.). Ecologia de pescadores da Mata Atlântica. São Paulo: Hucitec, Nepam/Unicamp: FAPESP, 2004.

PNUD - PROGRAMA DE LAS NACIONES UNIDAS PARA EL DESARROLLO. Informe sobre desarrollo humano 2010.Madri: Ediciones Mundi-Prensa, 2011. 
RAFFESTIN, C. Por uma geografia do poder. São Paulo: Ática, 1993.

SAMPAIO, C. A.C. (Org.). Gestão que privilegia uma outra economia: ecossocioeconomia das organizações.Blumenau: EDIFURB, 2010.

SAMPAIO, C. A. C.; LESAMA, M. F.; ARAUJO, J. R.; CEBERIO de León, I. Acuerdo socioproductivo y político de base territorial, ecologicamente sustentable y solidaria: posibilidades al desarrollo del Litoral Paranaense. In: BIENAL DEL COLOQUIO DE TRANSFORMACIONES TERRITORIALES, 8., 2010, Buenos Aires. Anais...Buenos Aires: Asociación de Universidades Grupo Montevideo (AUGM), 2010.

SANTOS, M. A Natureza do espaço - Técnica e tempo, razão e emoção. São Paulo: Editora da Universidade de São Paulo, 2006.

Sociedade e espaço: formação espacial como teoria e como método. In: Espaço e Sociedade: Ensaios. 2. ed. Petrópolis: Vozes, 1982.

SCHIMINSKI, B. Caminhos do Paraná no século XIX. In: Monografias: Universidade Tuiuti do Paraná, História, 2010.

SILVA, J. G. da; DEL GROSSI, M. E. O novo rural brasileiro. In: IAPAR - Instituto Agronômico do Paraná. ORNAS: Ocupações Rurais não-agrícolas. In: OFICINAS DE ATUALIZAÇÃO TEMÁTICA. Anais... Londrina, 2000.

WACKERNAGEL, M.; REES, W. Nuestra huella ecológica. Buenos Aires: LOM Ediciones, 2001. (Colección Ecologia\&Médio Ambiente).

WANDERLEY, M. de N. B. Raízes históricas do campesinato brasileiro. In: ENCONTRO ANUAL DA ANPOCSGT 17 Processos Sociais Agrários, 20., 1996, Caxambu,. Anais...Caxambu, 1996.

WEBER, M. Economia e sociedade. Brasília: Editora da Universidade de Brasília, 1999.

Artigo recebido em: 06/07/2015. Aceito para publicação em: 04/09/2015. 